\title{
The Stability of Oxygen-Free Copper Processed by High-Pressure Torsion after Room Temperature Storage for 12 Months
}

\author{
Meshal Y. Alawadhi*, Shima Sabbaghianrad, Yi Huang ${ }^{*}$, Terence G. Langdon
}

[*] Dr. Meshal Y. Alawadhi

Department of Manufacturing Engineering, College of Technological Studies, P.A.A.E.T, P.O. Box 42325, Shuwaikh 70654, Kuwait

Dr. Shima Sabbaghianrad

Departments of Aerospace \& Mechanical Engineering and Materials Science, University of Southern California, Los Angeles, CA 90089-1453, USA

[*] Dr. Yi Huang

Department of Design and Engineering, Faculty of Science and Technology, Bournemouth University, Poole, Dorset BH12 5BB, UK

Materials Research Group, Department of Mechanical Engineering, University of Southampton, Southampton SO17 1BJ, UK

Prof. Terence G. Langdon

Materials Research Group, Department of Mechanical Engineering, University of Southampton, Southampton SO17 1BJ, UK

Departments of Aerospace \& Mechanical Engineering and Materials Science, University of Southern California, Los Angeles, CA 90089-1453, USA

\begin{abstract}
.
Ultrafine-grained copper samples produced by high-pressure torsion were stored at room temperature for 12 months to investigate microstructural stability and the self-annealing phenomena. The results show that samples processed by low numbers of turns exhibit less thermal stability after storage for 12 months by comparison with samples processed by high numbers of turns. A significant decrease in the hardness was recorded near the edges of the discs processed by $1 / 4,1 / 2$ and 1 turn due to recrystallization and grain growth whereas a
\end{abstract} through the copyediting, typesetting, pagination and proofreading process, which may lead to differences between this version and the Version of Record. Please cite this article as doi: $\underline{10.1002 / \text { adem.201901015 }}$ 
minor drop in hardness values was observed in the samples processed by 3, 5 and 10 turns. This drop in hardness was related to a recovery mechanism.

Keywords: High-pressure torsion, Recrystallization, Self-annealing, Softening, Ultrafine grains

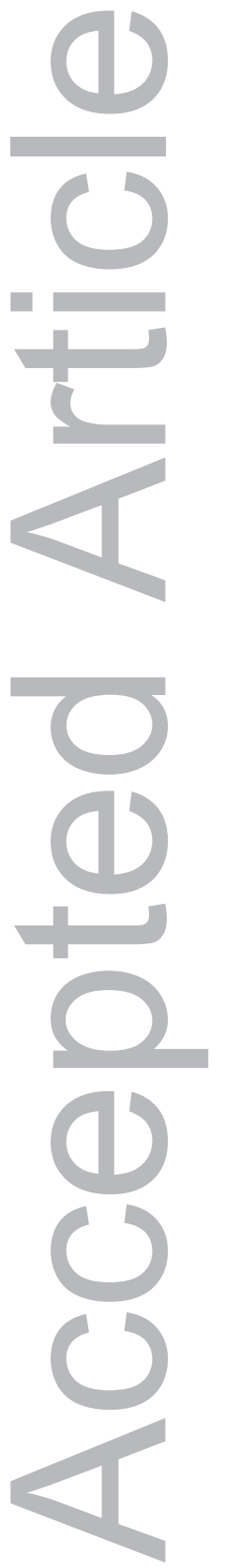




\section{Introduction}

High-pressure torsion (HPT) is an important severe plastic deformation (SPD) technique used to fabricate ultrafine-grained (UFG) and nano-crystalline materials with superior strength and hardness $[1,2]$. Bulk polycrystalline materials undergoing HPT will exhibit exceptional grain refinement producing a final microstructure with micro- or nanosized grains and with grain boundaries having high angles of misorientation [3]. The HPT process consists of using thin discs or ring-shaped samples and subjecting to a high pressure together with concurrent torsional straining which is produced by two massive anvils. The equivalent von Mises strain imposed on the disc can be calculated using the following equation [4]:

$$
\varepsilon_{e v}=\frac{2 \pi N r}{h \sqrt{3}}
$$

where $\mathrm{N}$ is the total number of turns, $\mathrm{r}$ is the radius of the disc and $\mathrm{h}$ is the thickness (or height) of the disc. According to Equation 1, the equivalent von Mises strain is directly proportional to the distance from the centre of the disc. This implies that the imposed strain is zero at the disc centre and a maximum at the edge, thereby leading to inhomogeneities in the microstructures after processing by HPT. In practice, experiments show that the microstructures of most metals tend to transform from an inhomogeneous to homogeneous state after the disc have been processed through a series of revolutions [5]. By conducting a microstructural analysis and characterizing the microhardness of each disc, the effect of straining on the transformation of the microstructural homogeneity can be evaluated. The results show a general agreement with the theoretical relationship in the early stages of straining where inhomogeneity is present and there are higher hardness properties near the edge compared with the centre of the disc. 
Although many studies showed that hardness in pure copper reaches a saturation state after imposing a certain level of strain by HPT [6-8], there are only limited reports on the significance of self-annealing at room temperature (RT) in pure copper after HPT. One study showed that self-annealing was not observed and there was no decrease in hardness after 70 days storage at RT for pure $\mathrm{Cu}(99.99 \%)$ subjected to HPT for 5 turns at $6.0 \mathrm{GPa}$ [9]. Another study on pure $\mathrm{Cu}$ processed by HPT for 1 turn and stored at RT for 96 hours revealed no significant change in hardness but there was a minor drop in the microstrain as measured by XRD [10]. Other HPT investigations showed that in high-purity oxygen-free high conductivity copper the hardness initially increased during the early stages of straining and then decreased and finally increased again in order to attain homogeneity, where the softening of the material was attributed to a dynamic recrystallization of the microstructure [11]. Self-annealing after HPT was investigated using $\mathrm{Cu}(99.99 \%)$ that was processed through 10 turns at $6.0 \mathrm{GPa}$ and then stored at RT for 4.3 years where the results showed a minor drop in the hardness value of $\sim 22 \mathrm{Hv}$ [12]. A recent study on $\mathrm{Cu}(99.99 \%)$ processed by HPT for $1 / 2,1,5$ and 10 turns at $6.0 \mathrm{GPa}$ showed a significant drop in hardness values at the edges of the disc processed by $1 / 2$ turn after RT storage for 6 weeks but the self-annealing effect was not detected after 5 and 10 turns [13]. The softening of copper was significant after short-term storage which causes a reduction in strength due to the self-annealing effect at RT. More recently, long-term self-annealing of HPT-processed $\mathrm{Cu}(99.99 \%)$ was investigated after storage at RT for 1.25 years and 7 years [14]. It is concluded from these reports that self-annealing of $\mathrm{Cu}$ may have a significant impact on the material performance in any industrial applications and accordingly it is essential to achieve a better understanding of the nature of this self-annealing effect. 
The present study was initiated in order to investigate the stability of oxygen-free copper after long-term storage at RT and, in addition, to provide a systematic study of the influence of this self-annealing on the microstructure and microhardness.

\section{Experimental Materials and Procedures}

The material used in this study was a high purity oxygen-free copper rod with a 99.95 $\mathrm{wt} \%$ purity. Initially the rod was annealed for $1 \mathrm{~h}$ at $600{ }^{\circ} \mathrm{C}$ using a vacuum tube furnace and then discs were cut with diameters of $10 \mathrm{~mm}$ and thicknesses of $\sim 0.85 \mathrm{~mm}$. The discs were processed by HPT under an applied pressure of $6.0 \mathrm{GPa}$ at RT with a rotation speed of $1 \mathrm{rpm}$ to the following total numbers of turns, $\mathrm{N}: 1 / 4,1 / 2,1,3,5$ and 10 . The HPT processing was conducted under quasi-constrained conditions where there is a small outflow of material around the edge of the disc between the two anvils $[15,16]$. Following HPT, discs were placed in storage at RT for periods of 1 week and 12 months.

Sample preparation was performed on both the HPT-processed discs and the postHPT stored discs. This consisted of grinding on SiC papers to remove layers of $\sim 0.1 \mathrm{~mm}$ thickness from the disc surfaces, followed by mechanical polishing using 9, 6, 3 and $1 \mu \mathrm{m}$ diamond suspensions and finally polishing to a mirror-like finish using a vibratory polisher with $0.04 \mu \mathrm{m}$ colloidal silica.

The Vickers microhardness, Hv, was measured on the polished samples using an FM300 microhardness tester equipped with a Vickers indenter. Each indentation was performed using a load of 100 gf with a dwell time of 15 s. Measurements were taken at positions along the disc diameters separated by incremental distances of $0.3 \mathrm{~mm}$ and with the average hardness at each position estimated from four individual points recorded around the selected position and separated by distances of $0.15 \mathrm{~mm}$. 
An electron backscattered diffraction (EBSD) analysis was conducted using an analytical field emission scanning electron microscope (SEM) JEOL JSM-7001F at an operating voltage of $15 \mathrm{kV}$ in order to examine the sample microstructure. The SEM was equipped with imaging detectors and used a TSL orientation imaging system and OIM ${ }^{\mathrm{TM}}$ software for data collection. Kikuchi patterns were obtained at a working distance of $15 \mathrm{~mm}$ with a sample tilt of 70 degrees. The step size was $0.2 \mu \mathrm{m}$, and the images were cleaned up using grain confidence index (CI) standardization, neighbour CI correlation and grain dilation procedures. The average grain size was determined using the linear intercept method.

The microstructures of the HPT-processed discs were evaluated using a Bruker D2 Phaser X-ray diffractometer equipped with a $\mathrm{Cu}$ target using $\mathrm{Cu} \mathrm{K} \alpha 1 / \mathrm{K} \propto$ (wavelength $\succsim 1.5418 \AA ̊$ ) radiation and a Ni K $\beta$ filter (detector side) with a 1D LYNXEYE detector. A corundum sample was run on the $\mathrm{x}$-ray machine for the calibration of instrumental broadening. It is important to note that the whole disc surface was analysed by X-ray diffraction (XRD) and $\theta-2 \theta$ scans were conducted from $2 \theta 30^{\circ}-100^{\circ}$ with scan steps of $0.02^{\circ}$ to record the XRD patterns. All of the XRD patterns were corrected for instrumental broadening. The crystallite size, the lattice parameter and the microstrain were calculated based on the Rietveld method [17] using Maud software for profile fitting.

\section{Experimental Results}

\subsection{The Evolution of Microhardness after Storage at RT}

The hardness measurements were recorded along a diameter of each disc and Fig. 1 compares the hardness measurements recorded after 1 week (solid points) and after 12 months (open points) following HPT processing for (a) 1/4, (b) $1 / 2$, (c) 1 , (d) 3 , (e) 5 and (f) 10 turns. Due to the time taken for EBSD sample preparation and observation, hardness measurements were carried out only after one week in order to provide comparable results for hardness and EBSD. The hardness results show that in the initial stages of deformation, 
where $\mathrm{N}=1 / 4,1 / 2$ and 1 turn in Fig. 1(a)-(c), the microhardness values vary significantly across the diameters of the discs with low hardness values recorded in the central regions with higher values at the edges. After later stages of deformation, at $\mathrm{N}=3,5$ and 10 turns in Fig. 1(d)-(f), there are only minor changes in the hardness values across the diameters of the discs. An essentially steady-state condition was achieved after 10 turns with reasonable hardness homogeneity. In addition, the hardness values recorded at the peripheries after 1/4 turn are higher than the values recorded at the same positions after subsequent turns. Thus, these values slightly decreased with increasing numbers of turns until they became stabilized with the same average of hardness values across the disc diameter. This decrease in hardness provides evidence for dynamic recovery taking place during the HPT process. It is noted that structural recovery was also observed in an earlier report of high purity OFHC copper of 99.99+wt $\%$ after processing by HPT at RT [13].

For specimens stored at RT for a period of 12 months after HPT processing, the microhardness measurements were again recorded along diameters of each disc and it is readily apparent in Fig. 1(a) that there was a significant drop in hardness around the periphery after 1/4 turn. The severity of the hardness loss was reduced as the point of measurement moved towards the centre of the disc. A major drop was visible at a radial distance of $\sim 4.0$ $\mathrm{mm}$ up to $\sim 4.8 \mathrm{~mm}$ corresponding to the furthest measurement from the centre, but it is reasonable to assume the drop in hardness extends to the edge of the disc. The average hardness value decreased from $\sim 138 \mathrm{Hv}$ to $\sim 100 \mathrm{Hv}$ within this region. In Fig. 1(b) the hardness values recorded after 12 months for the specimen processed by $1 / 2$ turn revealed a substantial drop over a distance of $\sim 2.0$ to $\sim 4.8 \mathrm{~mm}$ from the centre of the disc, with average hardness values decreasing from $\sim 138 \mathrm{Hv}$ to $\sim 100 \mathrm{Hv}$ within this region. For the specimen processed by 1 turn in Fig. 1(c), the hardness drop started at a point closer to the centre of the disc, with the decrease in hardness beginning at $\sim 0.5 \mathrm{~mm}$ from the centre of the disc and 
stabilising at an average value of $\sim 118 \mathrm{Hv}$ towards the periphery. It can be seen that at higher numbers of turns, as at $\mathrm{N}=3,5$ and 10 turns in Fig. 1(d), (e) and (f), respectively, the drop in hardness was not localized and the hardness was almost constant across the diameters of the discs. These latter three conditions exhibited similar trends in which the drop in hardness values were relatively minor with the hardness reduced by only $\sim 8 \%$ after storage at RT for 12 months.

\subsection{Microstructural Evolution after Room Temperature Storage}

Fig. 2 and Fig. 3 show the OIM images of, respectively, the centre and edge of the discs after 1 week (upper) and 12 months (lower) of HPT processing for, reading from left to right, 1/2,1,3 and 10 turns. In the disc centre area, as shown in Fig. 2, the 1/2 and 1turn discs have coarse grain structures after 1 week of HPT processing whereas the discs subjected to 5 and 10 turns of HPT processing have very fine grain structures. In the disc edge area, Fig. 3 shows very fine microstructures after 1 week in all samples processed through $1 / 2,1,3$ and 10 turns. Close inspection of the images in Fig. 3 shows that the grains at the periphery grew significantly after 12 months storage for $1 / 2$ turn. It is also apparent that the peripheries of the discs processed by 1 and 3 turns and then stored for 12 months have coarser grains than those present at 1 week after HPT processing.

To provide a quantitative summary of the data, Table 1 documents the average grain sizes of the centre and edge positions after HPT processing for various numbers of turns and with subsequent storage at RT for 1 week and 12 months. It can be seen that the average grain sizes at the centre and edge after 12 months were larger, for every number of turns, than the average grain sizes measured after 1 week from HPT processing.

Some abnormal grain growth was observed at the edge of the $1 / 2$ turn specimen, as indicated by the arrows in Fig. 3. Thus, the average grain size increased from $\sim 0.69 \mu \mathrm{m}$ to $\sim 3.1 \mu \mathrm{m}$. This is consistent with the localized reduction in hardness recorded in Fig. 1(b). It is 
also apparent that the rate of grain growth was slower in the discs processed by higher numbers of turns and the rate of grain growth decreased with increasing numbers of turns. For example, the average grain size at the edge after 1 turn increased from $\sim 0.63 \mu \mathrm{m}$ to $\sim 1.96$ $\mu \mathrm{m}$ after 12 months storage whereas the average grain size after 10 turns increased from $\sim 0.51 \mu \mathrm{m}$ to $\sim 0.71 \mu \mathrm{m}$ for the same storage conditions.

The distributions of the misorientation angles at the centre and edge positions for discs stored at RT for 12 months after HPT processing are shown in Fig. 4. Thus, the fractions of low-angles grain boundaries (LAGBs, defined as misorientations of $2-15^{\circ}$ ) are considerably higher at the centres of the discs processed by $1 / 2$ and 1 turn in Fig. 4(a) and (c) while there are high numbers of $\Sigma 3$ twin boundaries $\left(60^{\circ}\right)$ at the edges in Fig. 4(b) and (d). By contrast, the number of $\Sigma \mathfrak{3}$ twin boundaries $\left(60^{\circ}\right)$ was lower after 3 turns and instead the fractions of high-angle grain boundaries (HAGBs, defined as $>15^{\circ}$ ) were $\sim 80 \%$ at the centre and $\sim 91 \%$ at the edge, respectively. This difference in the distributions of misorientation angles between the centre and edge was further reduced at higher numbers of turns so that after 10 turns the fractions of HAGBs were $\sim 90 \%$ and $\sim 93 \%$ at the centre and edge, respectively.

The fractional numbers of different grain boundary characters are summarised in Fig. 5 at the edges of the discs measured within 1 week after HPT processing and after subsequent storage at RT for 12 months for (a) 1/2 turn, (b) 1 turn, (c) 3 turns and (d) 10 turns and similar information is given in Fig. 5(e-h) for the centres of the discs. The three sets of grain

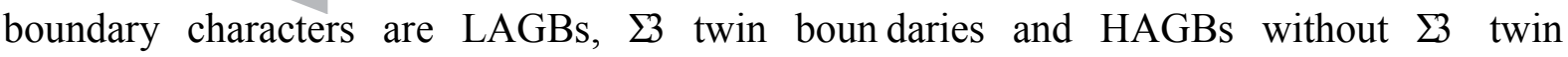
boundaries (labelled as $>15^{\circ}$ grain boundary character in Fig. 5).

For the edges of the discs, it is readily apparent in Fig. 5(a) and (b) that there was a drastic decrease in the fractional number of LAGBs after 12 months storage in those 
specimens processed by $1 / 2$ and 1 turn, and the fractional numbers of HAGBs without $\Sigma 3$ twin boundaries were slightly increased. However, the fraction of $\Sigma \mathcal{Z}$ twin boundaries significantly increased after storage at RT for 12 months. The grain boundary characters were relatively stable at higher numbers of turns, as at $\mathrm{N}=3$ and 10, and in Fig. 5(c-d) there are only minor changes in the fractional numbers. For the centres of the discs in Fig. 5(e-h), the fractional numbers of all boundaries were reasonably similar after 1 week and storage for 12 months.

It can be concluded from the significant reduction in hardness at the peripheries of the specimens processed by $1 / 4,1 / 2$ and 1 turns, and the significant increase in the $\Sigma \mathbb{3}$ twin boundaries, that recrystallization took place during storage for 12 months at RT. The recovery process taking place in the centres of the discs can be confirmed by the increase of the fraction of low-angle boundaries during long-term storage as shown in Fig. 5(e) and (f).

\subsection{X-Ray Diffraction Analysis}

The XRD tests were conducted on the discs at 1 week and 12 months after HPT processing. The microstrains for each condition are compared in Fig. 6 and it is concluded that the microstrains measured after 12 months follow the same trend as after 1 week except that slightly lower values were observed after 12 months storage at RT. For both plots, there is a sharp increase in microstrain from 0 to $1 / 2$ turn but thereafter there is a substantial decrease which continues up to 3 and 10 turns. This drop in the microstrain from 1 turn to 10 turns is consistent with the advent of dynamic recovery during HPT processing.

\section{Discussion}

\subsection{Instantaneous Softening during HPT processing}

The microhardness measurements recorded across the diameters of the discs in Fig. 1 within 1 week after HPT processing show that the peripheral areas of the discs processed by 
3, 5 and 10 turns exhibit lower hardness values than at the disc edges after processing by lower numbers of turns. This is consistent with the occurrence of dynamic recovery during the HPT processing. Several models have been developed to detect the nature of the recovery in materials based on the variations of microhardness with the equivalent strain [18-20]. The variation of microhardness recorded in this study with respect to the equivalent strain is depicted in Fig. 7(a) and this curve demonstrates the transition from an initial hardening to a subsequent softening of the oxygen-free copper during HPT. In practice, there is an abrupt increase in hardness in the initial stage of straining, followed by a drop in hardness at an equivalent strain of $\sim 12$ and then the hardness reaches a steady-state value of $\sim 130 \mathrm{Hv}$ at equivalent strain larger than $\sim 50$. These results are fully consistent with those reported in an earlier study on OFHC $\mathrm{Cu}(99.99+$ wt.\%) [13]. In another study on high purity $\mathrm{Cu}(99.99$ wt.\%) it was reported that the hardness saturates at a value of $\sim 130 \mathrm{Hv}$ at an equivalent strain of $\sim 15$ [21] whereas OFHC $\mathrm{Cu}(99.99+$ wt. $\%)$ revealed a saturation hardness of $\sim 150 \mathrm{Hv}$ at an equivalent strain of $\sim 22$ [11]. In a later study of pure $\mathrm{Cu}(99.99 \%)$, the hardness saturated at $\sim 142 \mathrm{Hv}$ at an equivalent strain of $\sim 80$ [22].

Hardening and then softening with rapid recovery has been reported in metals having high stacking-fault energy (SFE) such as high-purity aluminum [7, 23-31] and also in pure $\mathrm{Mg}$ [34] and pure $\mathrm{Zn} \mathrm{[29].} \mathrm{However,} \mathrm{it} \mathrm{has} \mathrm{been} \mathrm{well} \mathrm{documented} \mathrm{that} \mathrm{pure} \mathrm{Cu}$ generally saturates at large strains without recovery [7, 21, 33-41]. Thus, recovery occurs easily in high-purity Al due to the narrow separation between the partial dislocations in high SFE materials which leads to easy cross-slip. By contrast, pure copper is a low to medium SFE material so that cross-slip is more difficult due to the wider separation of the partial. Nevertheless, there is evidence for softening with rapid recovery in the oxygen-free $\mathrm{Cu}$ (99.95 wt.\%) used in the present HPT processing and similar findings were also reported in earlier studies on OFHC Cu $(99.99+$ wt.\%) processed by HPT at RT $[11,13,14]$ and OFHC 
$\mathrm{Cu}$ processed by repetitive upsetting-extrusion (RUE) at RT [42]. All of these results suggest that the nature of the recovery in oxygen-free copper may be different from other samples of pure copper having different purities.

The direct correlation between the Vickers microhardness values and the equivalent strain shown in Fig. 7(a) suggests a hardness softening indicative of the occurrence of recovery. Furthermore, the decrease in microstrain values shown in Fig.6 provide supporting evidence for dynamic recovery during the HPT processing. It is suggested from these data that recovery takes place after 1 turn and becomes more pronounced at higher numbers of turns. These results are generally consistent with an earlier study on $\mathrm{OFHC} \mathrm{Cu}(99.99+$ wt.\%) [13].

One parameter that may produce recovery is the temperature rise occurring during the HPT process which has been well documented by finite element modelling $[16,43]$. The results from this modelling show that the temperature rises due both to the heat generated during the plastic deforming of the sample and to the friction inherent in the material flow during the anvil rotation. Accordingly, it is important to investigate the influence of a temperature rise on the occurrence of recovery in the present study.

The variation of the temperature, $\Delta T$, with time is calculated by [44]:

$$
\Delta T=0.22 \sigma \omega\left[1+1.28\left(1-e^{-(t / 482)}\right)\right]
$$

where $\sigma$ is the flow stress (the values were determined using tensile testing as shown in Table $2), \omega$ is the rotation rate and $t$ is the time. The calculated temperature rise during each rotation is shown in Table 2 . The results demonstrate that the temperature of the oxygen-free $\mathrm{Cu}$ disc increased rapidly from $293 \mathrm{~K}(\mathrm{RT})$ to $\sim 309 \mathrm{~K}$ after $1 / 4$ turn and then the increase became slower with additional HPT turns. This is consistent with earlier results from finite element modelling that show a rapid increase in temperature in the initial stages of 
deformation followed by a slower rise [16]. The calculated increase in temperature after 10 turns is $\sim 35 \mathrm{~K}$. This value is similar to an earlier study on pure $\mathrm{Cu}$ that estimated a temperature rise of $\sim 40 \mathrm{~K}$ after 10 turns using the same experimental conditions [45].

Careful inspection of the microhardness results across the diameters of the HPT discs in the present study, combined with results obtained in earlier studies on OFHC $\mathrm{Cu}$, shows two different trends in the early stages of deformation where $\mathrm{N}=1 / 4,1 / 2$ and 1 turn. The first trend is a low hardness value in the central region of the disc and high values at the edges [13] which is similar to the present study. The second trend shows a low hardness value at the central region of the disc and a significant drop in hardness at the edges, with this drop in hardness moving towards the centre with increasing strain [11]. A reasonable hardness homogeneity was achieved after 10 turns in both examples. The present study shows that both trends may occur during the HPT processing of oxygen-free $\mathrm{Cu}$. Thus, a close inspection of the study conducted on OFHC Cu $(99.99+w t \%)$ shows the first trend was observed when the microhardness test was conducted at $24 \mathrm{~h}$ after HPT processing. The second trend appeared after 6 weeks of storage at RT and was due to the self-annealing effect [13]. These results are consistent with the present study of oxygen-free $\mathrm{Cu}(99.95 \mathrm{wt} . \%)$ where the first trend appeared during HPT processing and this transformed into the second trend after 12 months of storage at RT.

It is well established in the present study that dynamic recovery occurred at large strain during the HPT process. Also, it appears from the OIM images in Fig. 3 that there are dislocation-free grains which indicate that recrystallization may occur during or after the HPT processing. An earlier report suggested that softening of pure $\mathrm{Cu}$ is due to static recrystallization that takes place after the HPT processing [21] whereas dynamic recrystallization was reported in other studies $[45,46]$. In addition, several studies reported the occurrence of dynamic recrystallization in pure $\mathrm{Cu}$ in the early stages of deformation [11, 
$22,47]$. In order to more fully clarify the validity of these two phenomena, it will be important in future experiments to record the time of storage between the HPT processing and any mechanical testing and microstructural characterization.

\subsection{The occurrence of self-annealing after 12 months storage at RT}

Fig. 1(a)-(f) show the microhardness values recorded across the diameters of the discs 1 week and 12 months after HPT processing. It is well documented in Fig. 1(a)-(c) that specimens processed through a low number of turns, such as $\mathrm{N}=1 / 4,1 / 2$ and 1 , display a Vshaped plot due to the variations of the imposed strain across the disc, whereas specimens processed by high numbers of turns, such as $\mathrm{N}=3,5$ and 10 , display relatively uniform hardness distributions across the diameters of the discs. The present results reveal that selfannealing took place in oxygen-free copper after 12 months storage at RT and this selfannealing was most significant in specimens processed through a small number of turns, such as $1 / 4,1 / 2$ and 1 turn, and it was reduced at higher numbers of turns. This is clearly observed in Fig. 7(b) which shows a variation of hardness values with equivalent strain after 12 months of room temperature storage. This is similar to the trend observed after 1 week of room temperature storage shown in Fig. 7(a), however lower hardness values were recorded across all specimens after storage of 12 months. Similarly, a recent report demonstrated this behaviour with three distinctive stages (I. hardening, II. softening, and III. saturation) that varies with the values of the equivalent strain [14]. Stage I occurs at low equivalent strain and it is related to the accumulation of dislocations density, stage II occurs at moderate equivalent strain and it is related to the inhomogeneity of the microstructure, and stage III takes place at higher equivalent strain and is related to the stability of microstructure having HAGBs. 
It is readily apparent from microhardness measurements across the diameters of the discs that the hardness values drop drastically at the periphery and Fig. 3 provides evidence of abnormal grain growth after 12 months of storage at RT in the specimen processed by $1 / 2$ turn where there is a mixture of large and ultrafine grains. These large grains appear to be free of dislocations but this abnormal grain growth is associated with a significant increase in the fraction of $\Sigma 3$ boundaries as shown in Fig. 5(a) indicating recrystallization occurred during the time of storage. These data are consistent with other results showing abnormal grain growth containing a large fraction of $\Sigma 3$ boundaries mixed with ultrafine grains after 6 weeks of storage at RT of OFHC Cu after processing by HPT for $1 / 2$ turn [13]. An earlier study justified the occurrence of the abnormal grain growth due to the migration of the $\Sigma \mathbb{Z}$ boundaries [48]. Several studies have reported the occurrence of recrystallization and an increase in the fraction of $\Sigma 3$ boundaries in $\mathrm{Cu}$ due to adiabatic heating during the HPT process $[11,46,49,50]$. However, the temperature rise calculated from equation (2) is not sufficient to introduce dynamic softening during HPT processing which is in agreement with earlier studies reporting the same findings $[44,51]$.

The difference in the softening mechanisms between the centre and the edge of the disc is due to the difference in the internal stored energy between these two positions as a result of the variation of the strain imposed during the initial stages of HPT processing. A higher energy is stored at the edges of the disc in the form of additional dislocations which provide a strong driving force for recrystallization. It is well documented that recrystallization can occur in metals having heterogeneous microstructures as a result of a high strain energy gradient $[52,53]$. Another contribution to the driving force for recrystallization is the grain boundary energy. Since the disc edges exhibit smaller grain sizes, higher fractions of HAGBs and higher fractions of $\Sigma \mathfrak{3}$ twin boundaries compared to the disc centres, it is reasonable to anticipate that recrystallization is more pronounced at the 
peripheries. This is supported by a report for pure copper showing that recrystallization starts at positions with HAGBs during annealing at $160{ }^{\circ} \mathrm{C}$ [54]. Similar results were also observed in specimen processed by 1 turn but to a lesser extent.

It is apparent from inspection of Fig. 1(d)-(f) that a small decrease in hardness occurs across the discs after 12 months storage at RT for those discs processed by 3, 5 or 10 turns where this decrease is relatively uniform across the disc diameters. This finding is contrary to an earlier study which showed no drop in hardness for OFHC Cu discs processed by 5 and 10 turns and then stored for up to 6 weeks at RT [13]. The change in the fractions of HAGBs without twin boundaries and $\Sigma \mathfrak{Z}$ twin boundaries is insignificant during the storage time as shown in Fig. 5(c) and (d) whereas the microstrain is reduced as in Fig. 6. These results suggest that recovery took place after 12 months of storage at RT in those specimens processed through a high number of HPT turns.

The most interesting finding is that the occurrence of self-annealing is significant at the edges of the discs processed by a low number of turns but is relatively minor for discs processed by a large number of turns. This difference is due to the dynamic recovery which takes place during the HPT process at the edges of the discs at large numbers of turns, where this reduces the dislocation density and thereby reduces the driving force for recrystallization. It is readily apparent that recrystallization occurs preferentially at positions experiencing slow or no recovery. Furthermore, recovery reduces the internal stresses and dislocation density by the rearrangement of dislocations so that the driving force for recrystallization is diminished [55]. This is fully supported by calculating the microstrain from X-ray data which leads to a high microstrain after processing by $1 / 2$ turn and a low dislocation density after 10 turns as demonstrated by the results plotted in Fig. 6 . 
Microhardness, EBSD and XRD tests provide clear and consistent evidence that the occurrence of self-annealing is due to recovery and recrystallization. Recovery is a process in which cross-slip eradicates screw dislocations and climb annihilates edge dislocations. Thus, the rate of recovery is associated with the SFE which controls the degree of dislocation dissociation. The waiting time for cross-slip was calculated in an earlier study for FCC metals and the results show that recovery occurs easily in UFG $\mathrm{Cu}$ [56]. Additionally, the high densities of lattice defects induced by the HPT process stores an intensive amount of energy within the copper specimens which triggers a self-annealing effect in metals having medium melting temperatures $[12,57]$.

\section{Summary and Conclusions}

1. The microstructural stability of UFG oxygen-free copper processed by HPT was investigated after storing the samples for 1 week and for 12 months at RT.

2. A significant decrease in microhardness values was observed near the edges of the discs processed by low numbers of turns $(\mathrm{N}=1 / 4,1 / 2$ and 1) after 12 months of storage at RT. However, the reduction in hardness was not localized and was almost constant across the diameters of the discs for the samples processed through 3, 5 and 10 turns.

3. Microstructural investigation showed that self-annealing is related to recrystallization and grain growth at low numbers of turns whereas it is related to a recovery mechanism at larger numbers of turns.

4. The occurrence of self-annealing in the samples processed by lower numbers of turns is related to the higher stored energy by comparison with the samples processed by higher number of turns where the stored energy is lower due to the occurrence of dynamic recovery during HPT that diminished the driving force for recrystallization. 
5. The difference in the softening mechanisms between the centres and the edges of the discs processed by $1 / 4$ and $1 / 2$ turn is due to the difference in the internal stored energy between the two positions as a consequence of the variation in the strain imposed during the initial stages of HPT processing. A higher energy is stored at the edges of the disc in the form of additional dislocations which provide a driving force for recrystallization.

\section{Acknowledgements}

Meshal Alawadhi acknowledges the financial support provided by the Public Authority of Applied Education and Training for his PhD study.

\section{Conflict of Interest}

The authors declare no conflict of interest.

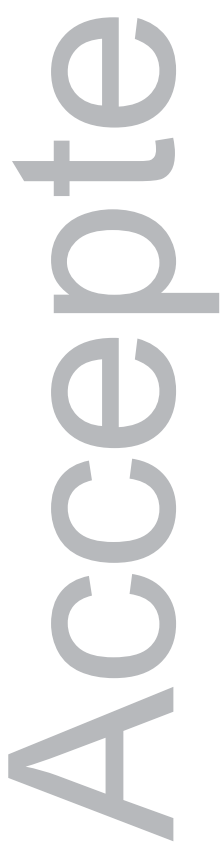




\section{References}

[1] A. P. Zhilyaev, T. G. Langdon, Prog. Mater. Sci. 2008, 53, 893.

[2] K. Edalati, Z. Horita, Mater. Sci. Eng. A 2016, 652, 325.

[3] J. Wongsa-Ngam, M. Kawasaki, T.G.Langdon, J. Mater. Sci. 2013, 48, 4653.

[4] R. Z. Valiev, Y. V. Ivanisenko, E. F. Rauch, B. Baudelet, Acta Mater. 1996, 44, 4705.

[5] Y. Estrin, A. Molotnikov, C. H. J. Davies, R. Lapovok, J. Mech. Phys. Solids. 2008, 56, 1186.

[6] Y. Z. Tian, S. D. Wu, Z. F. Zhang, R. B. Figueiredo, N. Gao, T. G. Langdon, Acta Mater. 2011, 59, 2783.

[7] K. Edalati, Z. Horita, T. Furuta, S. Kuramoto, Mater. Sci. Eng. A 2013, 559, 506.

[8] A. Y. Khereddine, F. H. Larbi, M. Kawasaki, T. Baudin, D. Bradai, T. G. Langdon, Mater. Sci. Eng. A 2013, 576, 149.

[9] H. Matsunaga, Z. Horita, Mater. Trans. 2009, 50, 1633.

[10] A. P. Zhilyaev, T. G. Langdon, J. Mater. Sci. 2014, 49, 6529.

[11] A. I. Almazrouee, K. J. Al-Fadhalah, S. N. Alhajeri, T. G. Langdon, Mater. Sci. Eng. A 2015, 641, 21.

[12] K. Edalati, J. M. Cubero-Sesin, A. Alhamidi, I. F. Mohamed, Z. Horita, Mater. Sci. Eng. A 2014, 613, 103.

[13] Y. Huang, S. Sabbaghianrad, A. I. Almazrouee, K. J. Al-Fadhalah, S. N. Alhajeri, T. G. Langdon, Mater. Sci. Eng. A 2016, 656, 55.

[14] A.I. Almazrouee, K.J. Al-Fadhalah, S.N. Alhajeri, Y. Huang, T.G. Langdon, Adv. Eng. Mater. 2019, 1801300, 1.

[15] R.B. Figueiredo, P.R. Cetlin, T.G. Langdon, Mater. Sci. Eng. A 2011, 528, 8198.

[16] R. B. Figueiredo, P.H.R. Pereira, M.T.P. Aguilar, P.R. Cetlin, T.G. Langdon, Acta Mater. 2012, 60, 3190.

[17] H.M. Rietveld, J. Appl. Crystallogr. 1969, 2, 65.

[18] M. Kawasaki, J. Mater. Sci. 2014, 49, 18.

[19] M. Kawasaki, B. Ahn, T. G. Langdon, Acta. Mater. 2010, 58, 919.

[20] M. Kawasaki, B. Ahn, T. G. Langdon: Mater. Sci. Eng. A 2010, 527, 7008.

[21] K. Edalati, Y. Ito, K. Suehiro, Z. Horita, Int. J. Mater. Res. 2009, 100, 1668.

[22] J. Xu, J. Li, C.T. Wang, D. Shan, B. Guo, T. G. Langdon, J. Mater. Sci. 2016, 51, 1923.

[23] C. Xu, Z. Horita, T.G. Langdon, Acta Mater. 2007, 55, 203.

[24] M. Kawasaki, S.N. Alhajeri, C. Xu, T.G. Langdon, Mater. Sci. Eng. A 2011, 529, 345.

[25] M. Kawasaki, B. Ahn, T. G. Langdon, J. Mater. Sci. 2010, 45, 4583.

[26] M. Kawasaki, R. B. Figueiredo, T. G. Langdon, Acta. Mater. 2011, 59, 308. 
[27] K. Edalati, Z. Horita, Mater. Sci. Eng. A 2011, 528, 7514.

[28] Y. Harai, Y. Ito, Z. Horita, Scr. Mater. 2008, 58, 469.

[29] Y. Ito, Z. Horita, Mater. Sci. Eng. A 2009, 503, 32.

[30] K. Edalati, Z. Horita, Mater. Trans. 2009, 50, 92.

[31] C. Xu, Z. Horita, T. G. Langdon, Mater. Trans. 2010, 51, 2.

[32] K. Edalati, A. Yamamoto, Z. Horita, T. Ishihara, Scr. Mater. 2011, 64, 880.

[33] A. P. Zhilyaev, A. A. Gimazov, T. G. Langdon, J. Mater. Sci. 2013, 48, 4461.

[34] T. Hebesberger, H. P. Stüwe, A. Vorhauer, F. Wetscher, R. Pippan, Acta. Mater. 2005, 53, 393.

[35] K. Edalati, T. Fujioka, Z. Horita, Mater. Sci. Eng. A 2008, 497, 168.

[36] X. H. An, S. D. Wu, Z. F. Zhang, R. B. Figueiredo, N. Gao, T. G. Langdon, Scr. Mater. 2010, 63, 560.

[37] J. Č́žek, M. Janeěk , O. Srba, R. Kužel, Z. Barnovská, I. Procházka, et al., Acta Mater. 2011, 59, 2322.

[38] H. Jiang, Y. T. Zhu, D. P. Butt, I. V. Alexandrov, T. C. Lowe, Mater. Sci. Eng. A 2000, 290, 128.

[39] A. Dubravina, M. J. Zehetbauer, E. Schafler, I. V. Alexandrov, Mater. Sci. Eng. A $2004387-389,817$.

[40] Z. Horita, T. G. Langdon, Mater. Sci. Eng. A 2005, 410-411, 422.

[41] K. Edalati, K. Imamura, T. Kiss, Z. Horita, Mater. Trans. 2012, 53, 123.

[42] I. Balasundar, K. R. Ravi, T. Raghu, Mater. Sci. Eng. A 2013, 583, 114.

[43] P.H.R. Pereira, R. B. Figueiredo, Mater. Trans. 2019, 60, 1139..

[44] P. H. R. Pereira, R. B. Figueiredo, Y. Huang, P. R. Cetlin, T. G. Langdon, Mater. Sci. Eng. A 2014, 593, 185

[45] K. Edalati, R. Miresmaeili, Z. Horita, H. Kanayama, R. Pippan, Mater. Sci. Eng. A 2011, 528, 7301 .

[46] A. P. Zhilyaev, S. Swaminathan, A. A. Gimazov, T. R. McNelley, T. G. Langdon, J. Mater. Sci. 2008, 43, 7451.

[47] M. V. Degtyarev, T. I. Chashchukhina, L. M Voronova, A. M. Patselov, V. P. Pilyugin, Acta Mater. 2007, 55, 6039.

[48] B. B. Straumal, O. A. Kogtenkova, A. S. Gornakova, V. G. Sursaeva, B. Baretzky, J. Mater. Sci. 2016, 51, 382.

[49] K. J. Al-Fadhalah, S. N. Alhajeri, A. I. Almazrouee, T. G. Langdon, J. Mater. Sci. 2013, 48, 4563.

[50] A. P. Zhilyaev, T. R.McNelley, T. G. Langdon, J. Mater. Sci. 2007, 42, 1517.

[51] K. Edalati, Y. Hashiguchi, P. H. R. Pereira, Z. Horita, T. G. Langdon, Mater. Sci. Eng. 
A 2018, 714, 167.

[52] G. Wang, S. D. Wu, L. Zuo, C. Esling, Z. G. Wang, G. Y. Li, Mater. Sci. Eng. A 2003, 346,83

[53] M. Kumar, A. J. Schwartz, W. E. King, Acta Mater. 2002, 50, 2599.

[54] S. Ferrasse, V. M. Segal, K. T. Hartwig, R. E. Goforth, Metall. Mater. Trans. A 1997,528A, 1047.

[55] H. P. Stüwe, A. F. Padilha, Jr. F. Siciliano, Mater. Sci. Eng. A 2002, 333, 361.

[56] J. Gubicza, N. Q. Chinh, J. L. Lábár, Z. Hegedüs, T. G. Langdon, Mater. Sci. Eng. A 2010, 527, 752 .

[57] K. Edalati, Y. Hashiguchi, H. Iwaoka, H. Matsunaga, R. Z. Valiev, Z. Horita, Mater, Sci. Eng A 2018, 729, 340.

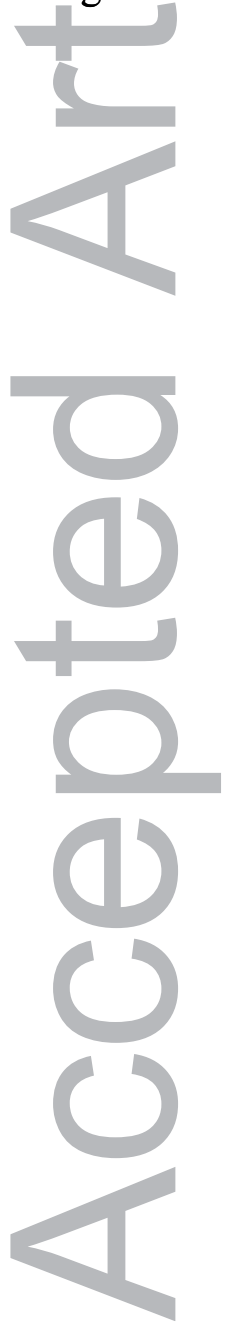




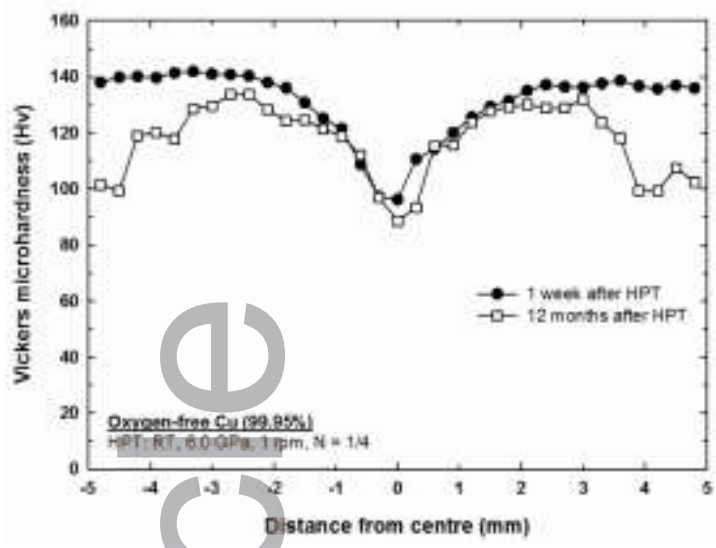

(a)

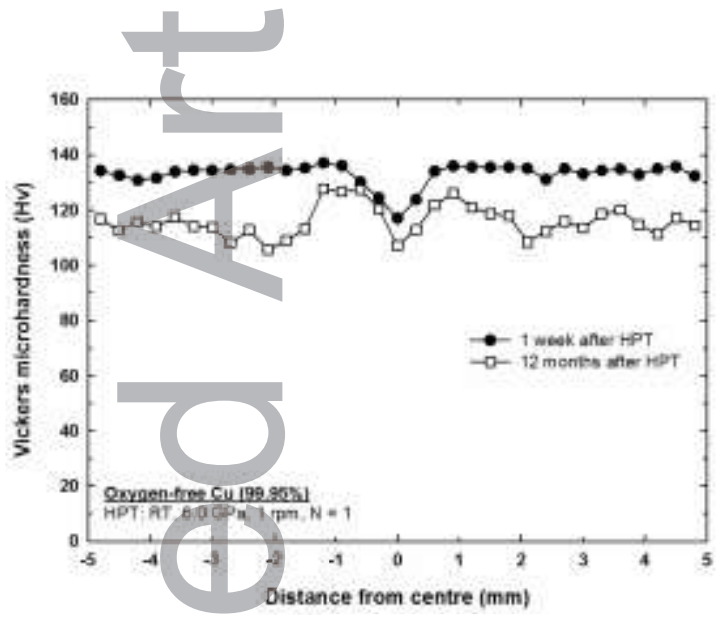

(c)

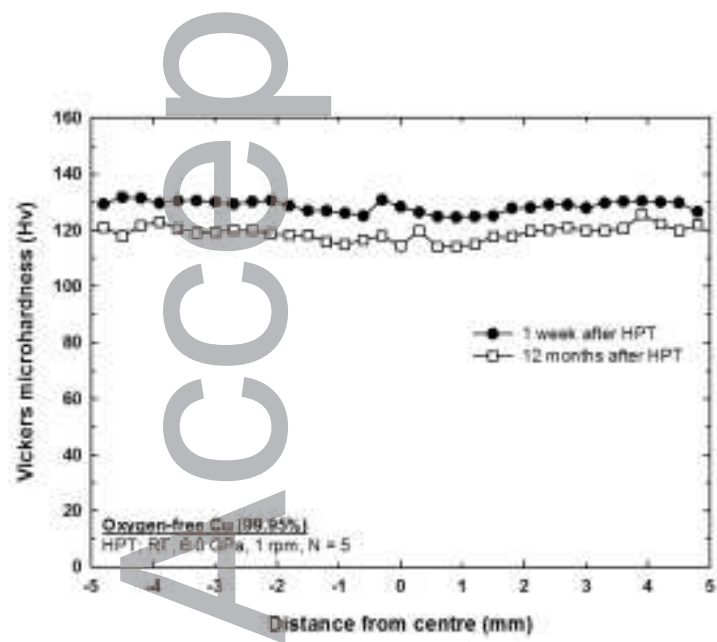

(e)

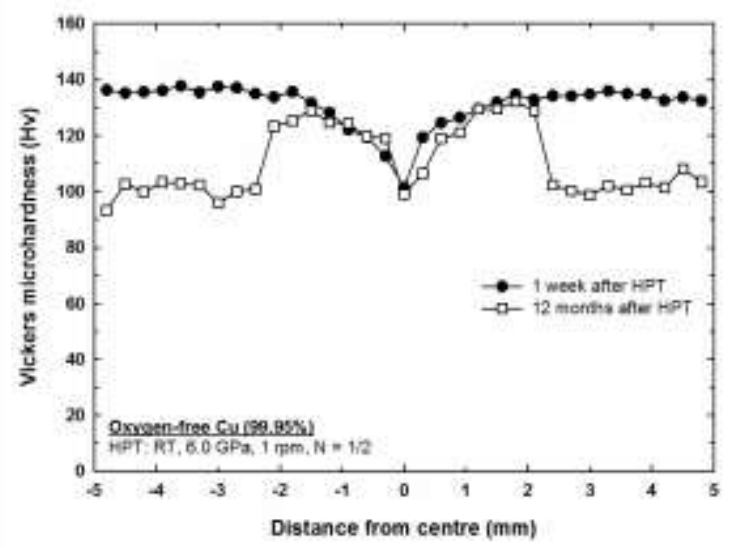

(b)

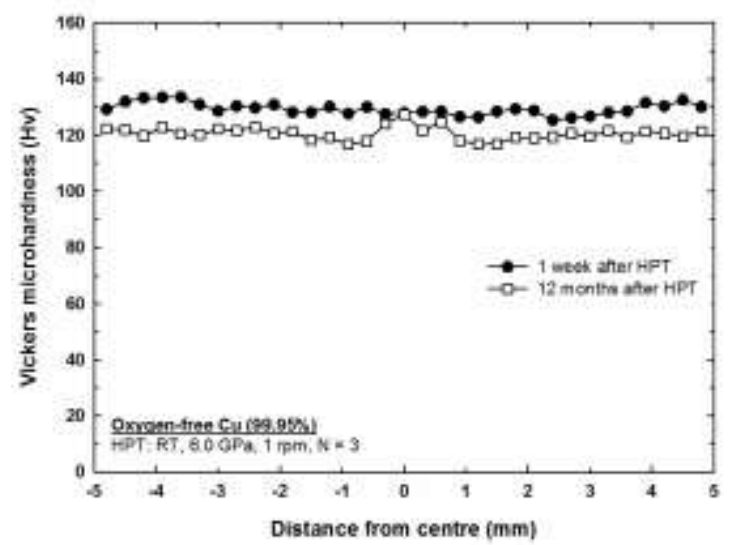

(d)

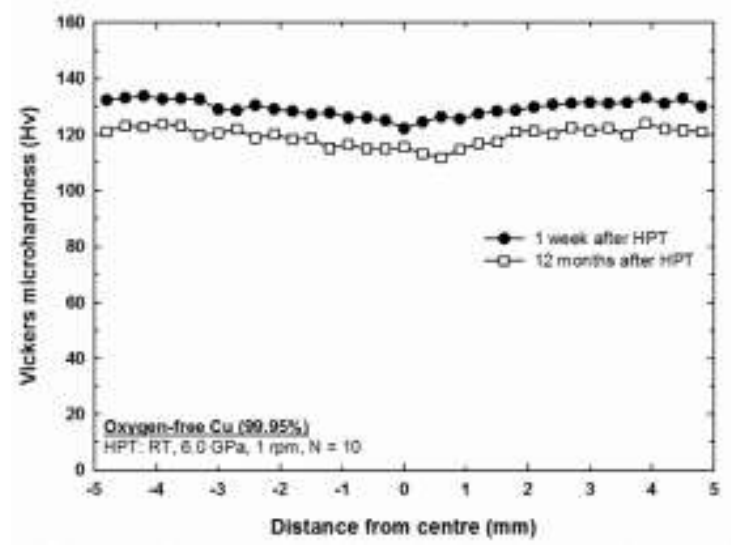

(f)

Fig. 1 Vickers microhardness measurements recorded along diameters of oxygen-free $\mathrm{Cu}$ discs after 1 week and 12 months of HPT processing for different numbers of turns (a) 1/4,
(b) $1 / 2$,
(c) 1 ,
(d) 3 ,
(e) 5 and
(f) $\quad 10$ turns. 

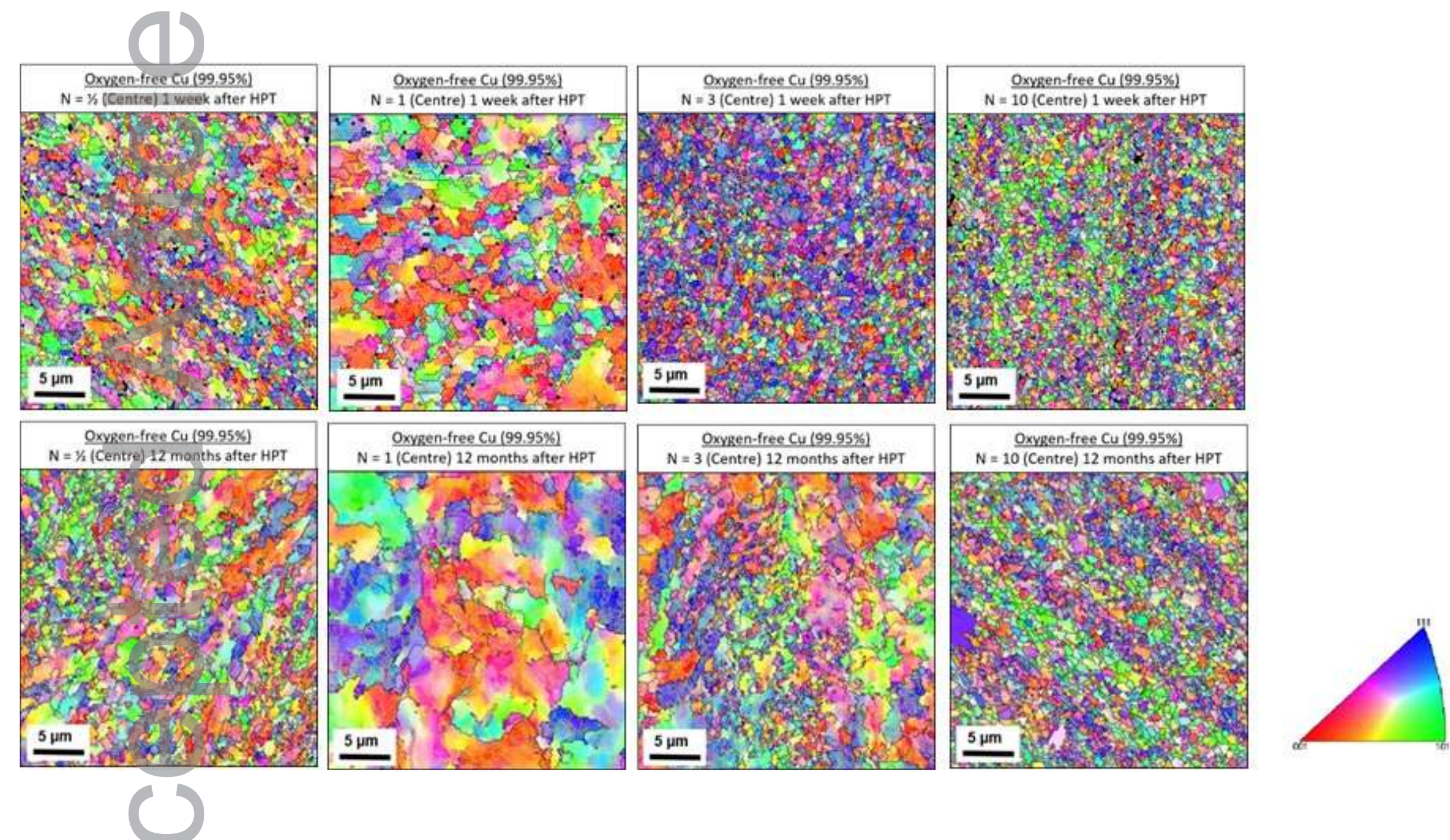

Fig. 2 OIM images of the central regions for oxygen-free copper discs 1 week (upper) and 12 months (lower) after HPT processing for 1/2, 1, 3 and 10 turns.

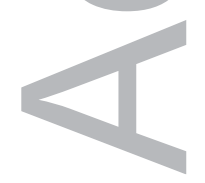

This article is protected by copyright. All rights reserved 

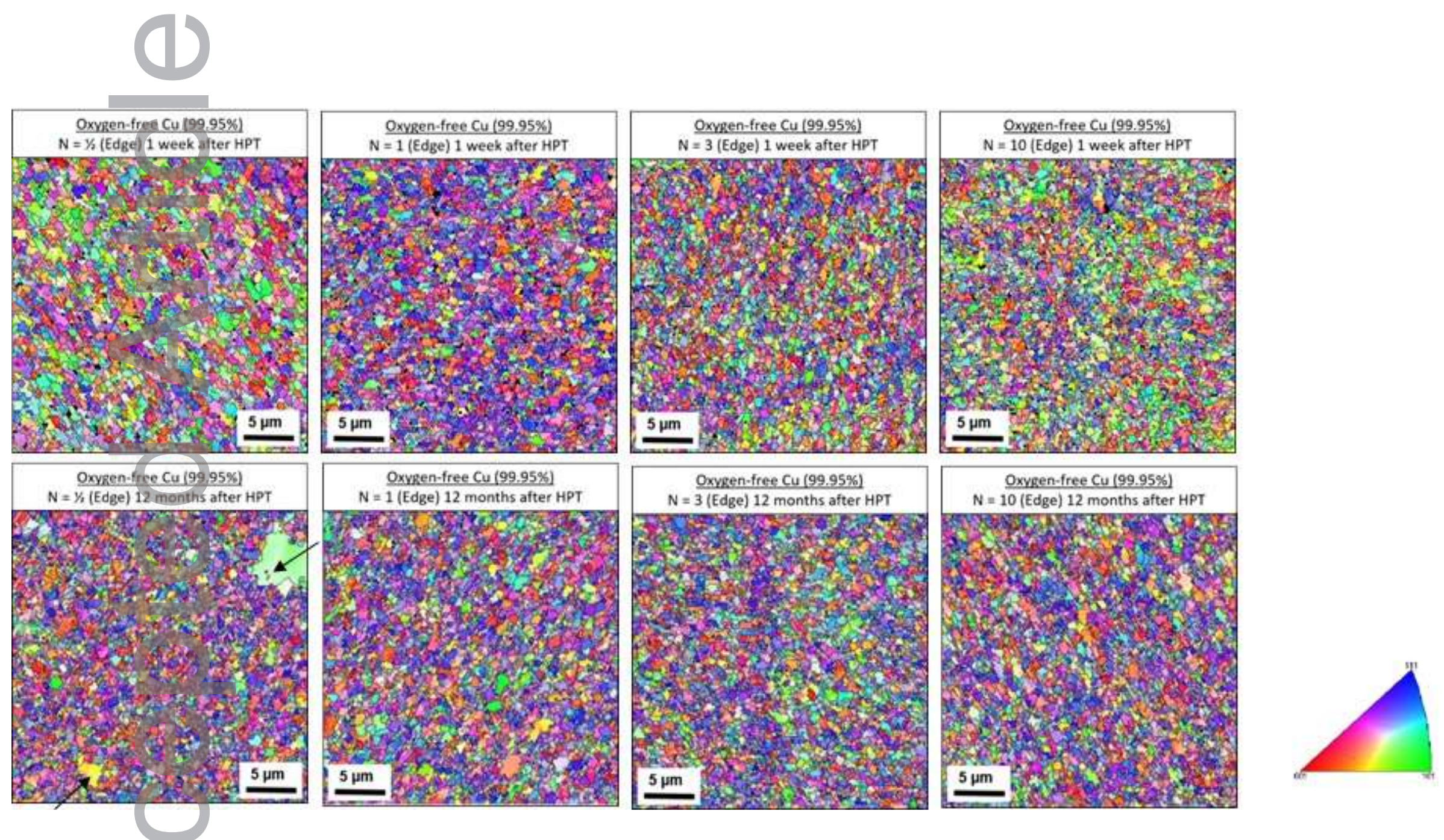

Fig. 3 OIM images of the peripheral regions for oxygen-free copper discs 1 week (upper) and 12 months (lower) after HPT processing for 1/2, 1, 3 and 10 turns: abnormal grain growth indicated by arrows.

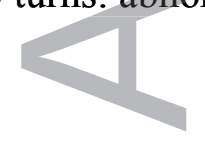

This article is protected by copyright. All rights reserved 

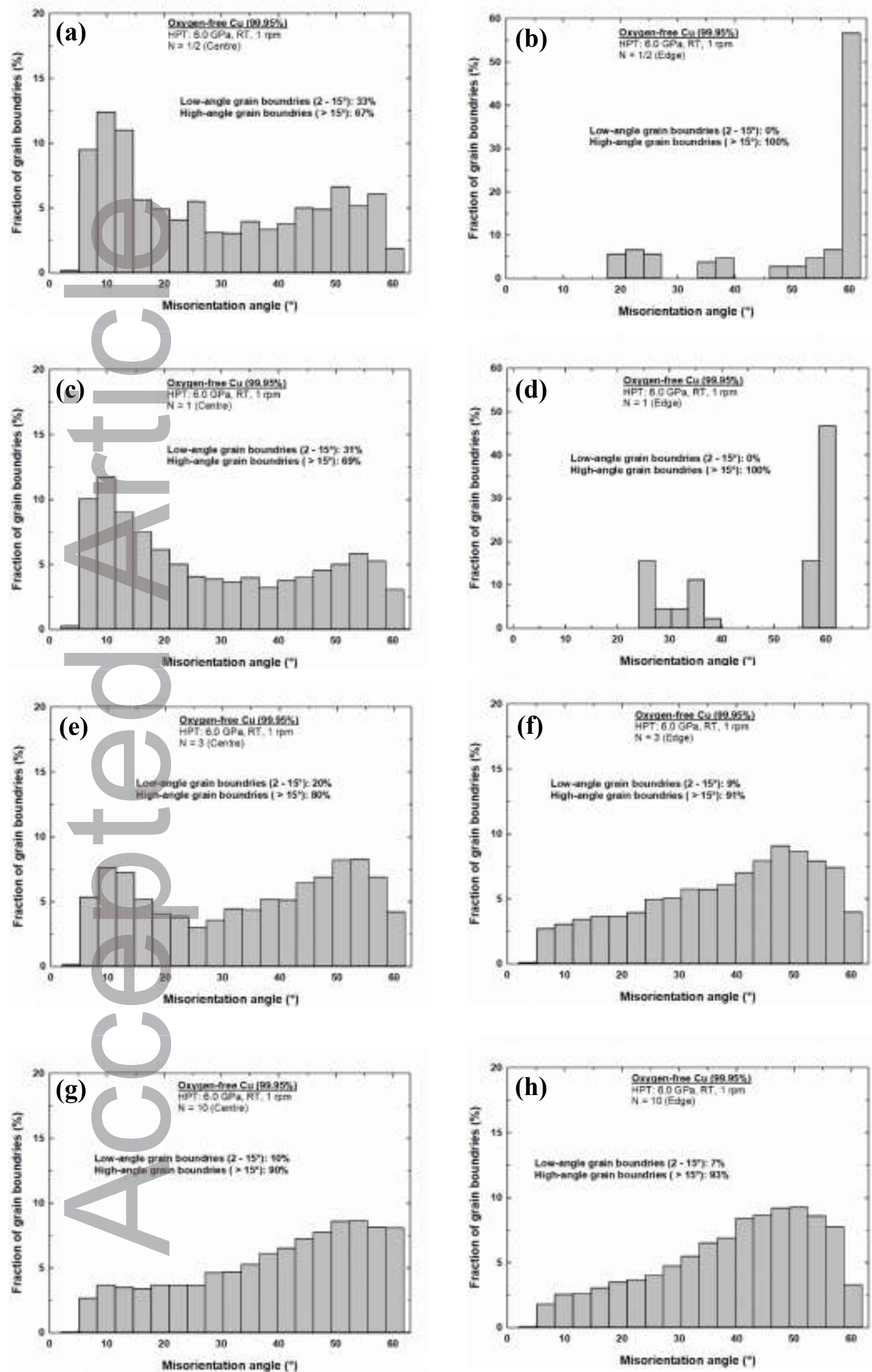

This article has been accepted for publication and undergone full peer review but has not been through the copyediting, typesetting, pagination and proofreading process, which may lead to differences between this version and the Version of Record. Please cite this article as doi: 10.1002/adem.201901015

This article is protected by copyright. All rights reserved 
Fig. 4 Distributions of misorientation angles for oxygen-free copper discs stored at RT for 12 months after HPT processing at the centre (left) and edge (right) after (a,b) 1/2, (c,d) 1, (e,f) 3 and $(\mathrm{g}, \mathrm{h}) 10$ turns.
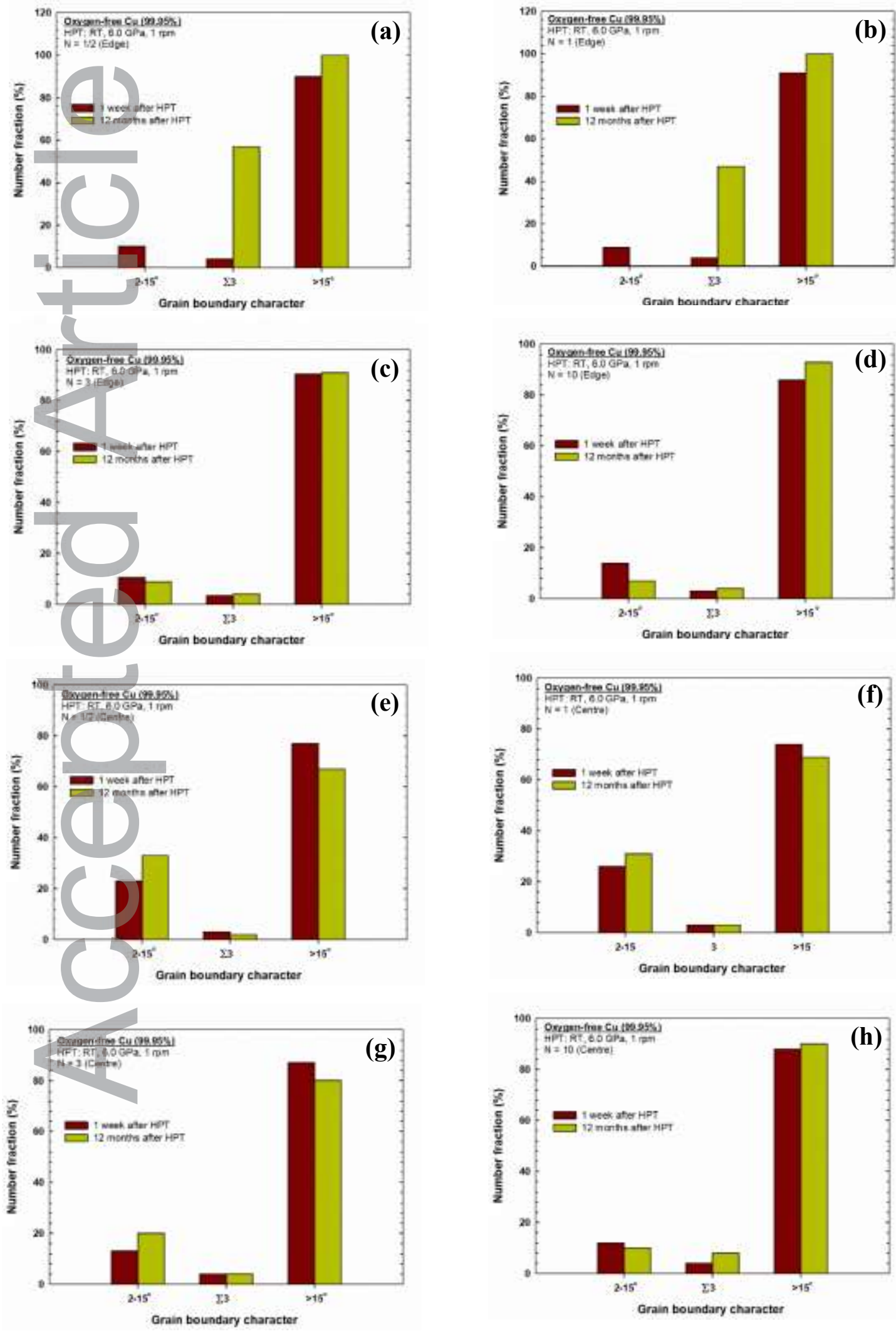
Fig. 5 The fractional numbers of different grain boundary characters for oxygen-free $\mathrm{Cu}$ discs measured within 1 week after HPT processing and after subsequent storage at RT for 12 months for (a) $\mathrm{N}=1 / 2$ (Edge), (b) $\mathrm{N}=1$ (Edge), (c) $\mathrm{N}=3$ (Edge), (d) $\mathrm{N}=10$ (Edge), (e) $\mathrm{N}=$ $1 / 2$ (Centre), (f) $\mathrm{N}=1$ (Centre), (g) $\mathrm{N}=3$ (Centre) and (h) $\mathrm{N}=10$ (Centre).

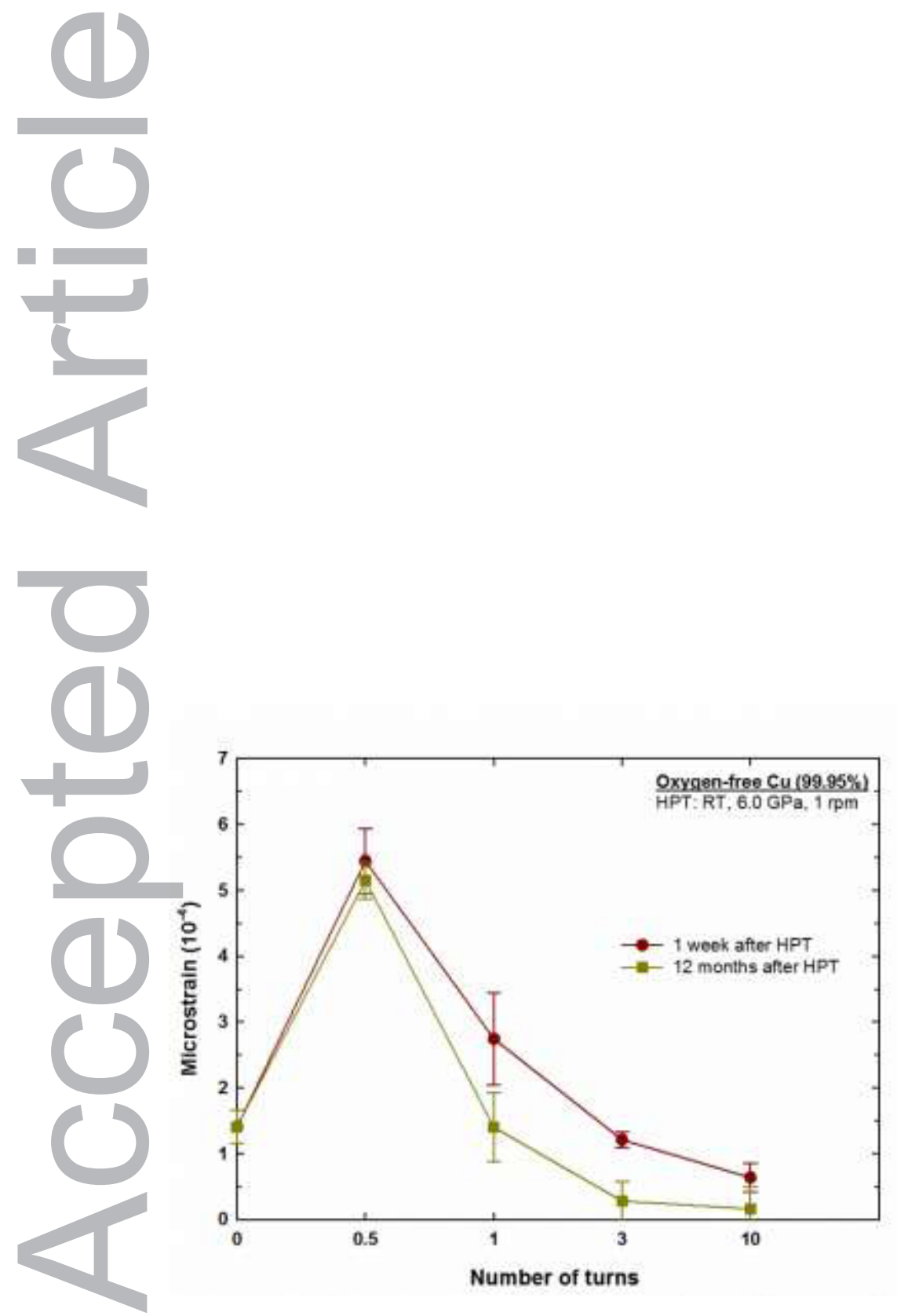

Fig. 6 Microstrain as a function of number of turns for oxygen-free copper stored at room temperature for 1 week and 12 months after HPT processing. 


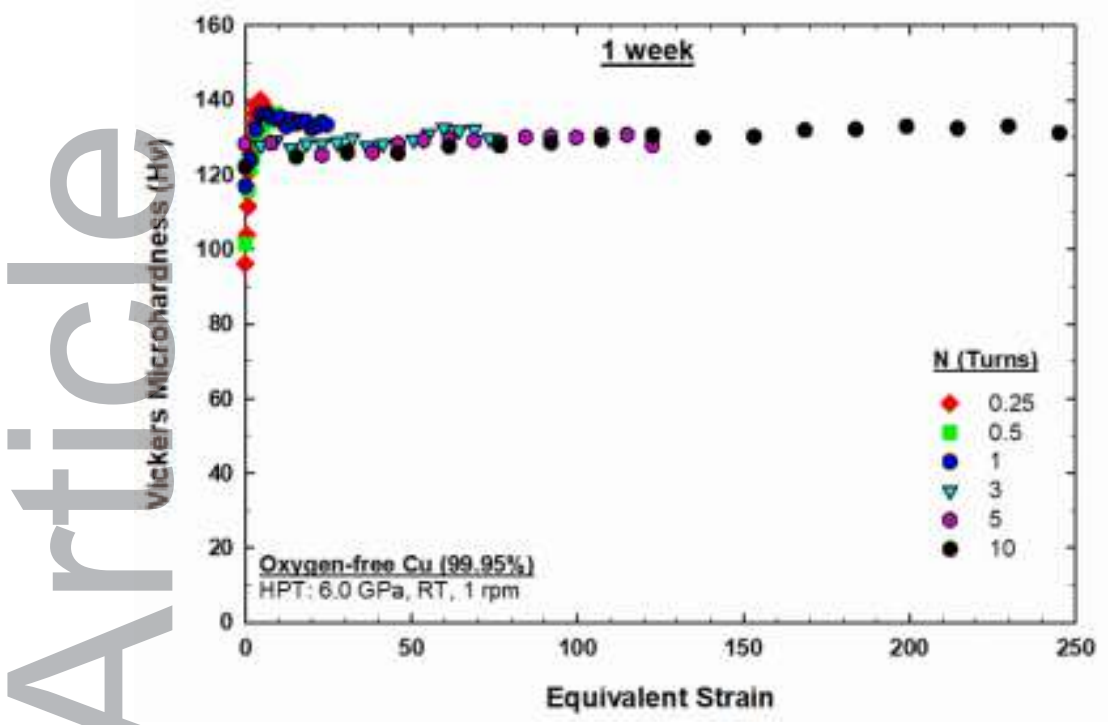

(a)

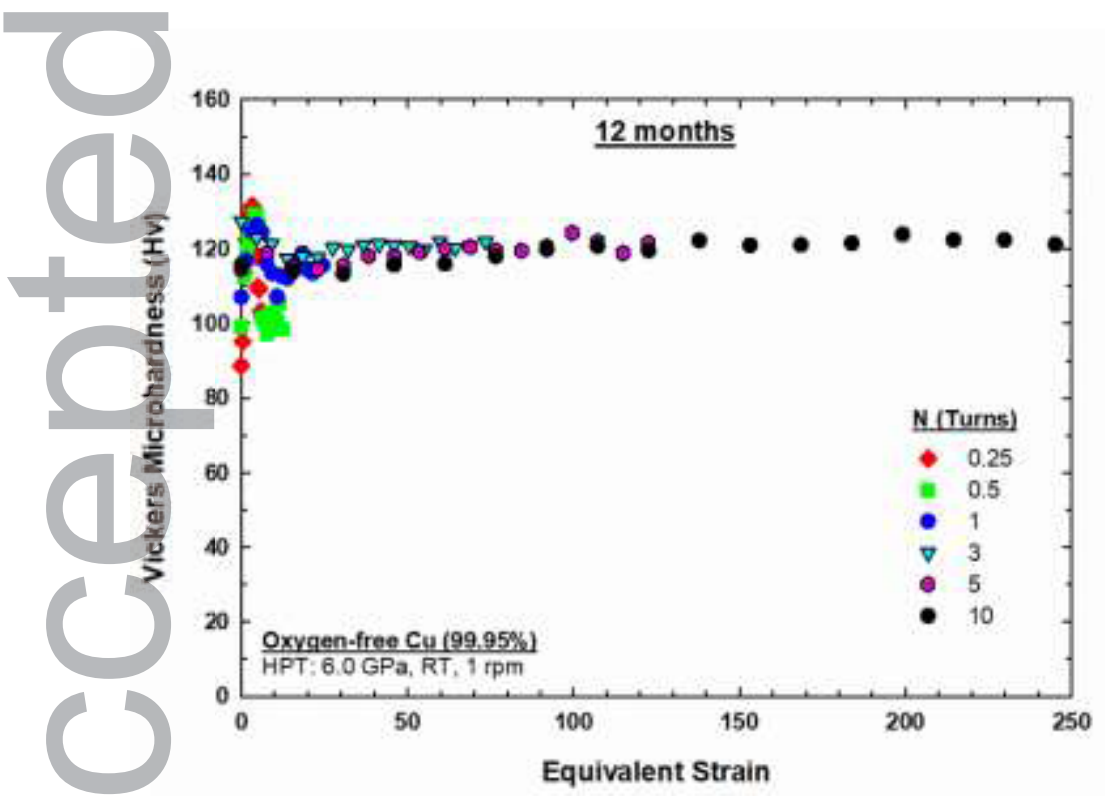

(b)

Fig. 7 Vickers microhardness values with respect to equivalent strain for oxygen-free $\mathrm{Cu}$ processed by HPT and placed in storage at RT for periods of: (a) 1 week and (b) 12 months. 
Table 1 The average grain sizes of the centres and edges of oxygen-free $\mathrm{Cu}$ discs after HPT processing for various number of turns and subsequent storage at RT for 12 months.

\begin{tabular}{|c|c|c|c|}
\hline \multirow{2}{*}{ No. of turns } & \multirow{2}{*}{ Position } & \multicolumn{2}{|c|}{ Grain Size $(\mu \mathrm{m})$} \\
\hline & & 1 week after HPT & $\begin{array}{l}12 \text { months after } \\
\text { HPT }\end{array}$ \\
\hline \multirow[t]{2}{*}{$1 / 2$ turn } & Centre & 0.82 & 1.04 \\
\hline & Edge & 0.69 & 3.10 \\
\hline \multirow[t]{2}{*}{1 turn } & Centre & 0.70 & 1.20 \\
\hline & Edge & 0.63 & 1.96 \\
\hline \multirow[t]{2}{*}{3 Turns } & Centre & 0.60 & 1.67 \\
\hline & Edge & 0.57 & 0.70 \\
\hline 10 Turns & Centre & 0.52 & 0.79 \\
\hline 1 & Edge & 0.51 & 0.71 \\
\hline
\end{tabular}

Table 2 The calculated temperature rise for different numbers of turns during HPT processing of Oxygen-free $\mathrm{Cu}$.

\begin{tabular}{cccc}
\hline Number of Turns (N) & $\boldsymbol{\sigma}(\mathbf{M P a})$ & $\mathbf{T}(\mathbf{K})$ & $\Delta \boldsymbol{T}(\mathbf{K})$ \\
\hline $\mathbf{0}$ & - & 295 & 0 \\
$\mathbf{1 / 4}$ & 475 & 309 & 14 \\
$\mathbf{1 / 2}$ & 530 & 311 & 16 \\
$\mathbf{1}$ & 472 & 311 & 16 \\
$\mathbf{3}$ & 496 & 317 & 22 \\
$\mathbf{5}$ & 494 & 322 & 27 \\
$\mathbf{1 0}$ & 491 & 330 & 35 \\
\hline
\end{tabular}




\title{
The Stability of Oxygen-Free Copper Processed by High-Pressure Torsion after Room Temperature Storage for 12 Months
}

\author{
Meshal Y. Alawadhi ${ }^{*}$, Shima Sabbaghianrad, Yi Huang ${ }^{*}$, Terence G. Langdon
}

[*] Dr. Meshal Y. Alawadhi (my.alawadhi@PAAET.EDU.KW)

Department of Manufacturing Engineering, College of Technological Studies, P.A.A.E.T, P.O. Box 42325, Shuwaikh 70654, Kuwait

Dr. Shima Sabbaghianrad

Departments of Aerospace \& Mechanical Engineering and Materials Science, University of Southern California, Los Angeles, CA 90089-1453, USA

[*] Dr. Yi Huang (yhuang2@,bournemouth.ac.uk)

Department of Design and Engineering, Faculty of Science and Technology, Bournemouth University, Poole, Dorset BH12 5BB, UK

Materials Research Group, Department of Mechanical Engineering, University of Southampton, Southampton SO17 1BJ, UK

Prof. Terence G. Langdon

Materials Research Group, Department of Mechanical Engineering, University of Southampton, Southampton SO17 1BJ, UK

Departments of Aerospace \& Mechanical Engineering and Materials Science, University of Southern California, Los Angeles, CA 90089-1453, USA

\section{Table of Contents (TOC) text}

Microstructural changes in the disc edge area of oxygen-free copper samples produced by $1 / 2$ turn of high-pressure torsion (HPT) processing include abnormal grain growth and a significant increase in the fraction of $\sum 3$ boundaries after 12 months storage at room temperature. These features confirm that there is self-annealing during 12 months storage in HPT-processed oxygen-free copper.

\section{TOC figure}
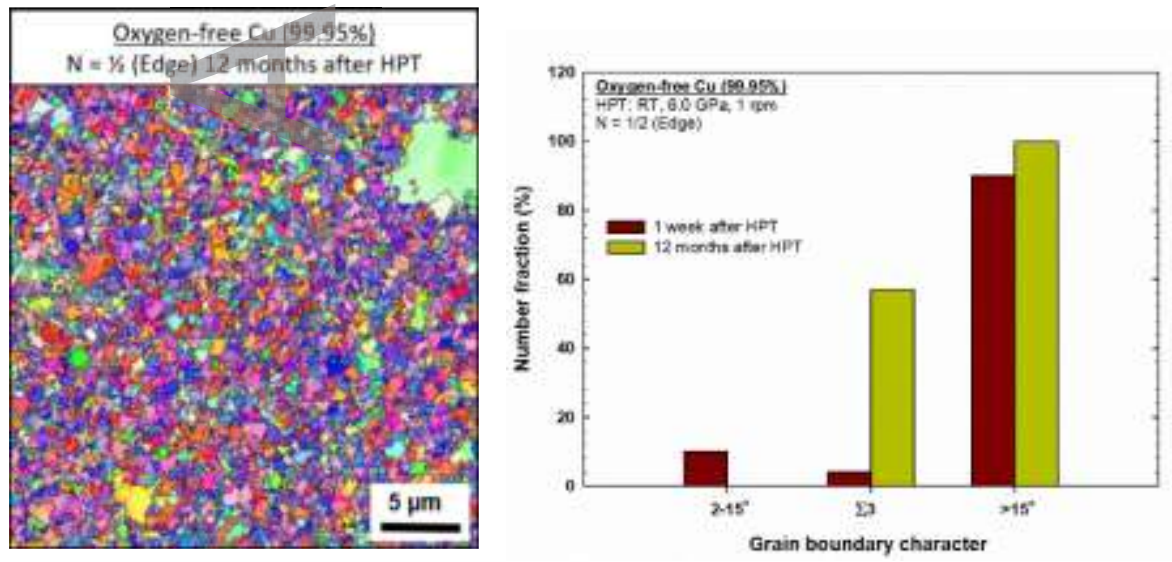